\title{
Transplantation of endothelial progenitor cells in treating rats with IgA nephropathy
}

\author{
Wei Guo ${ }^{1,2}$, Jiang-Min Feng ${ }^{2}$, Li Yao ${ }^{2}$, Li Sun ${ }^{2}$ and Guang-Qing Zhu ${ }^{3}$
}

\begin{abstract}
Background: Therapeutic options in IgAN are still limited. The aim of this study is to explore the feasibility of using endothelial progenitor cell to treat IgAN in rat model.

Methods: Rat bone marrow mononuclear cells (BM-MNCs) obtained with density gradient centrifugation were cultured in vitro, and induced into endothelial progenitor cells (EPCs). EPCs were identified by surface marker CD34, CD133 and VEGFR2 (FLK-1) and by Dil-Ac-LDL/FITC-UEA-1 double staining. EPCs were labeled with PKH26 prior to transplantation. Rat model of IgAN was established by oral administration of bovine serum albumin together with lipopolysaccharide via the caudal vein and subcutaneous injection of $\mathrm{CCL}_{4}$. Kidney paraffin sections were stained by H\&E and PAS. Immunofluorescence was used to assess IgA deposition in the glomeruli. Peritubular capillary (PTC) density was determined by CD31 staining. Monocyte chemoattrant protein-1 (MCP-1), hypoxia-inducible factor-1a (HIF-1a) and CD105 were also measured by immunohistochemistry, western blotting and real-time fluorescent quantitative PCR.

Results: The transplanted BM-EPCS were successfully located in IgAN rat kidney. After transplantation, Urinary red blood cell, urine protein, BUN, Scr and IgA serum level were significantly decreased, so were the areas of glomerular extracellular matrix and the IgA deposition in the glomeruli. In addition, PTC density was elevated. And the expression levels of HIF-1a and MCP-1 were significantly down-regulated, while the expression of CD105 was up-regulated. All these changes were not observed in control groups.
\end{abstract}

Conclusion: The BM-EPCs transplantation significantly decreases the expansion of glomerular extracellular matrix and the deposition of IgA in the glomeruli; lowers the expression of inflammatory factors; increases PTC density; improves ischemic-induced renal tissue hypoxia, all of which improves the renal function and slows the progress of IgA nephropathy.

Keywords: Endothelial progenitor cells, IgA nephropathy, Peritubular capillary, Transplantation

\section{Background}

IgAN, the most common form of glomerular disease throughout the world, was first reported by Berger and Hinglais in France in 1968 [1]. 25\% patients with IgAN will develop end stage renal diseases (ESRD), 5-25 years after the diagnosis of IgAN. However, the cause of primary IgAN and the mechanism defining mesangial IgA deposition in IgAN are unclear, and thus there has been no effective therapeutic treatment for patients with IgAN so far.

\footnotetext{
* Correspondence: fengjiangm@163.com

${ }^{2}$ Department of Nephrology, The First Affiliated Hospital of China Medical University, Shenyang 110001, China

Full list of author information is available at the end of the article
}

Glomerulosclerosis and interstitial fibrosis are irreversible pathological changes during the development of IgAN to ESRD. Therefore, the focus of our research on how to delay the progress of renal fibrosis in IgAN patients. Previous studies have shown that in IgAN patients, cell damage and apoptosis of renal microvascular endothelial cells and loss of PTC cause renal ischemia, hypoxia, activation of stromal cell, secretion of fibrosis cytokines, which leads to the upregulation of fibrosisrelated genes and accumulation of extracellular matrix (ECM) [2-5]. In 1997, Asahara et al. [6], for the first time, isolated and confirmed the existence of endothelial progenitor cells, which can differentiate into vascular

\section{Ciomed Central}

(c) 2014 Guo et al.; licensee BioMed Central Ltd. This is an Open Access article distributed under the terms of the Creative Commons Attribution License (http://creativecommons.org/licenses/by/2.0), which permits unrestricted use, distribution, and reproduction in any medium, provided the original work is properly credited. The Creative Commons Public Domain Dedication waiver (http://creativecommons.org/publicdomain/zero/1.0/) applies to the data made available in this article, unless otherwise stated. 
endothelial cells and can be used for angiogenesis in vivo. Currently, most studies suggest that the EPC is mainly derived from umbilical cord blood, adult bone marrow and peripheral blood [7]. Therefore, the aim of our study is to investigate whether BM-EPCs transplantation will be an effective therapeutic mean for IgAN patients.

\section{Methods}

Animal

The China medical university animal care and use Committee approved the procedures.

Female Sprague-Dawley (SD) rats, weighted 150-200 gram, were used in this study. The rats were maintained under a 12 hour light/dark cycle at a constant temperature $\left(22 \pm 1^{\circ} \mathrm{C}\right)$, with free access to clean water and normal chow. The rats were orally administrated with BSA (MBCHEM, USA) at dosage of $400 \mathrm{mg} / \mathrm{kg}$, continuously for 6 weeks. At the $6.8^{\text {th }}$ week, the rats received lipopolysaccharide (LPS) (AMRESCO Inc, Solon, OH, USA) injection via the caudal vein, at a dose of $0.25 \mathrm{mg} / \mathrm{kg}$. Then, the rats were received subcutaneous injection of $0.4 \mathrm{ml}$ castor oil and $0.1 \mathrm{ml}$ carbon tetrachloride $\left(\mathrm{CCL}_{4}\right)$ once a week, continuously for 9 weeks as described before, with slight modification [8-10]. To minimize the effect of $\mathrm{CCL}_{4}$ on liver, the dosage of $\mathrm{CCL}_{4}$ was reduced to one third of the dosage used for establishment of hepatic fibrosis

The IgAN rats were identified by measuring 24-hour urine protein, Urinary red blood cell, blood urea nitrogen (BUN), serum creatinine (Scr), as well as level of IgA. Meanwhile, Liver function was monitored by Alanine amino transferase (ALT), aspertate amino- transferase (AST) and $\gamma$-glutamyl- transferase (GGT) were tested. Each kidney was divided into 2 parts. The first part was embedded in paraffin and stained with hematoxylin and eosin (H\&E). The second portion was embedded in OCT and stored at $-70^{\circ} \mathrm{C}$ followed by frozen sectioning for immunofluorescence staining. Direct immunofluorescence (FITC-conjugated rabbit anti-rats IgA antibody from Dako, USA) was used to visualize the IgA deposition in the glomeruli. The IgA deposition was graded by a 5-stage semiquantitative method ( - to ++++$)$ : $(-)$, no staining under low magnification and possible staining under high magnification; (+), possible staining under low magnification and staining under high magnification; $(++)$, staining under low magnification and clear staining under high magnification; $(+++)$ clear staining under low magnification and bright staining under high magnification; $(++++)$, very intense staining under high magnification. Then, the IgAN model rats were randomly divided into two groups: IgAN group (IgAN + saline group, 6 rats) and EPC group (IgAN + endothelial progenitor cells, 30 rats). Normal rats receiving saline $(n=6)$ were used as control group. The study was approved by the Academic Review Board at China Medical University (see Additional file 1).
Table 1 Sequences of amplification primers for CD105, MCP-1, HIF-1 and $\beta$-actin

\begin{tabular}{llcc}
\hline Name & Sequence $\left(\mathbf{5}^{\prime} \neg \mathbf{3}^{\prime}\right)$ & Tm $\left({ }^{\circ} \mathbf{C}\right)$ & Size $(\mathbf{b p})$ \\
\hline CD105 F & ACTCGGGAGGTGTTCTGGTCTT & 63.1 & 211 \\
CD105 R & GTGCTGCTATGGAGGTAATGGTG & 61.4 & \\
MCP-1 F & TGAGTCGGCTGGAGAACTACAAG & 61.3 & 209 \\
MCP-1 R & AGGTGCTGAAGTCCTTAGGGTTG & 61.7 & \\
HIF1-aF & GCCTTAACCTATCTGTCACTTG & 55.9 & 250 \\
HIF1-aR & ATTGTCTTCTGCTCCATTCCAT & 58 & \\
$\beta$-actin F & GGAGATTACTGCCCTGGCTCCTAGC & 60.1 & 155 \\
$\beta$-actin R & GGCCGGACTCATCGTACTCCTGCTT & 62 & \\
\hline
\end{tabular}

\section{Culture and identification of EPCs}

EPCs were isolated and prepared by using the density gradient method, according to the previous description $[6,11,12]$. The femur and tibia of SD rats were separated under sterile conditions, from which bone marrow mononuclear cells were isolated. At $37^{\circ} \mathrm{C} 5 \% \mathrm{CO}_{2}$ incubator, the cells were seeded in 6-well plates, at $5 \times 10^{5}$ cells/well, in M199 medium supplied with VEGF $10 \mu \mathrm{g} / \mathrm{L}, \beta$-FGF $5 \mu \mathrm{g} / \mathrm{L}$, EGF $5 \mu \mathrm{g} / \mathrm{L}, \mathrm{IGF} 5 \mu \mathrm{g} / \mathrm{L}, 10 \%$ fetal bovine serum (HyClone Inc., Logan, Utah, USA). At day 14, the cells became spindle- shaped. The expression of CD34 (Santa Cruz Biotechnology, Inc, Santa Cruz, CA, USA), CD133 (Abnova Inc., Taipei, China) and VEGFR2 (Peprotech, Rocky Hill, NJ, USA) were identified by flow cytometer (BD Inc., San Jose, CA, USA). The EPCs were selected by Dil-ac-LDL/FITC-UEA-1(Molecular Probes, Eugene, OR) dual staining, and were labeled by PKH26 before prior to transplantation.

\section{Transplantation of EPCs}

EPCs were injected 3 days after the induction of $\operatorname{lgAN}$. EPC group rats received $3 \times 10^{6}$ cells per rat via the caudal vein $(0.5 \mathrm{ml} / \mathrm{rat})$. Other rats received same volume of

Table 2 Biochemical factors of normal and IgAN rats groups $(\bar{x} \pm s)$

\begin{tabular}{|c|c|c|}
\hline & Normal Group & IgAN Group \\
\hline Weight (gram) & $237.0 \pm 9.7$ & $204.5 \pm 7.1^{*}$ \\
\hline Urinary red blood cell count (cells/ $\mu \mathrm{L}$ ) & $4.82 \pm 1.6$ & $422.12 \pm 49.65^{*}$ \\
\hline Urine Protein (mg/24 h) & $9.94 \pm 4.03$ & $70.3 \pm 33.2^{*}$ \\
\hline BUN (mmol/L) & $6.57 \pm 0.49$ & $10.42 \pm 1.32^{*}$ \\
\hline $\operatorname{Scr}(\mu \mathrm{mol} / \mathrm{L})$ & $26.8 \pm 3.89$ & $52.8 \pm 6.76^{*}$ \\
\hline Serum $\lg A(\mu \mathrm{g} / \mathrm{ml})$ & $26.04 \pm 1.12$ & $28.99 \pm 1.30^{*}$ \\
\hline $\operatorname{ALT}(\mathrm{u} / \mathrm{L})$ & $34.17 \pm 3.87$ & $40.17 \pm 5.74$ \\
\hline AST (u/L) & $85.67 \pm 11.65$ & $90.5 \pm 13.05$ \\
\hline GGT (u/L) & $28.0 \pm 5.59$ & $28.17 \pm 5.53$ \\
\hline$A L B(g / L)$ & $40.67 \pm 4.72$ & $38.0 \pm 4.29$ \\
\hline
\end{tabular}

${ }^{*} P<0.01$, compare to normal group. 


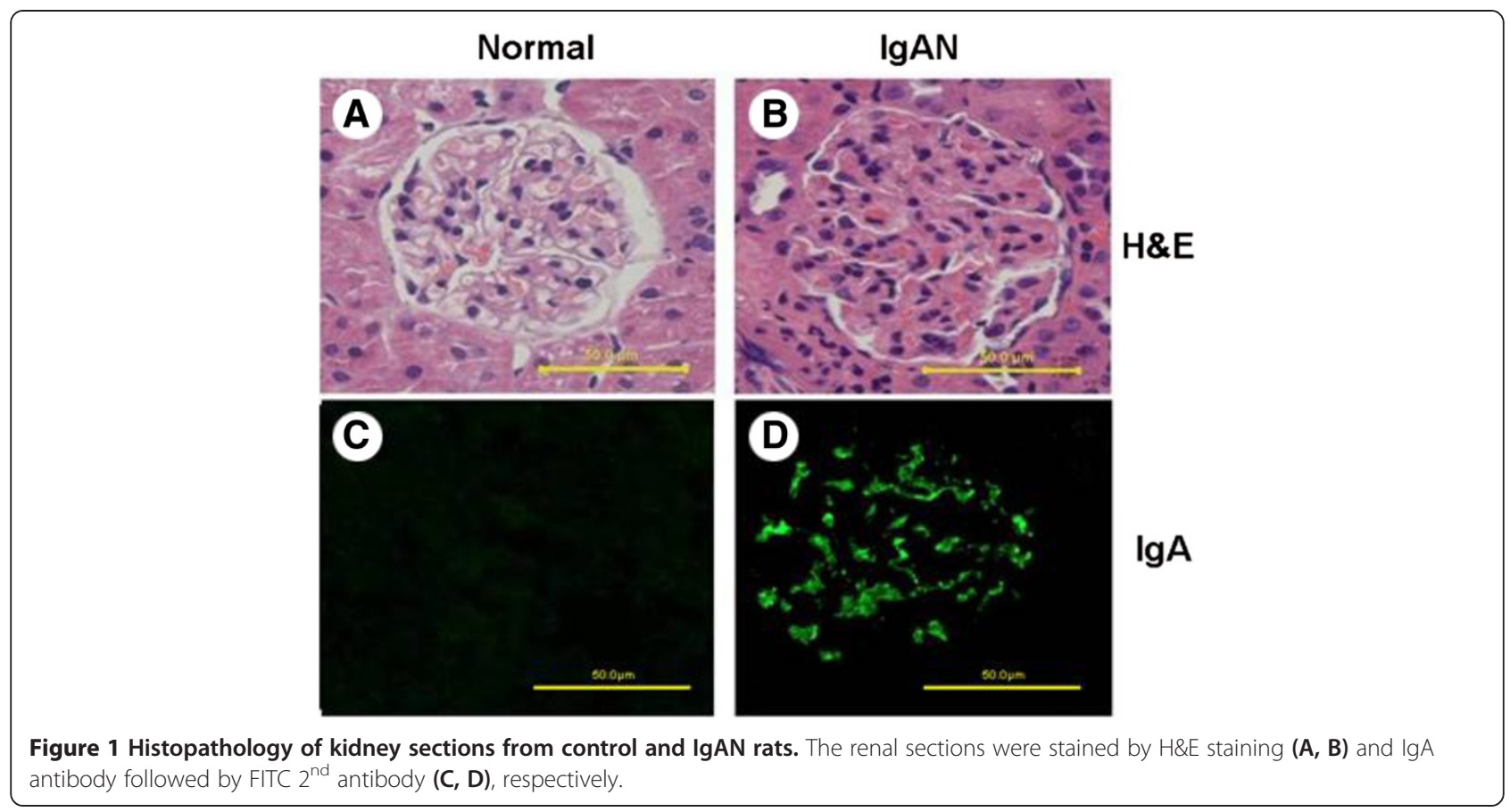

0.9\% saline. Six rats in EPC group were sacrificed at 1, 3, 7, 14 days after transplantation and 1 day before transplantation. Rats of other groups were sacrificed at 14 days after transplantation. 24 hour urine protein, Urinary red blood cell, BUN and Scr were examined for all rats. Each kidney was divided into three parts: one for pathological analysis and immunohistochemistry studies; The second portion was embedded in OCT for immunofluorescence staining; The third part was saved in liquid nitrogen for western blotting and real time RT-PCR.

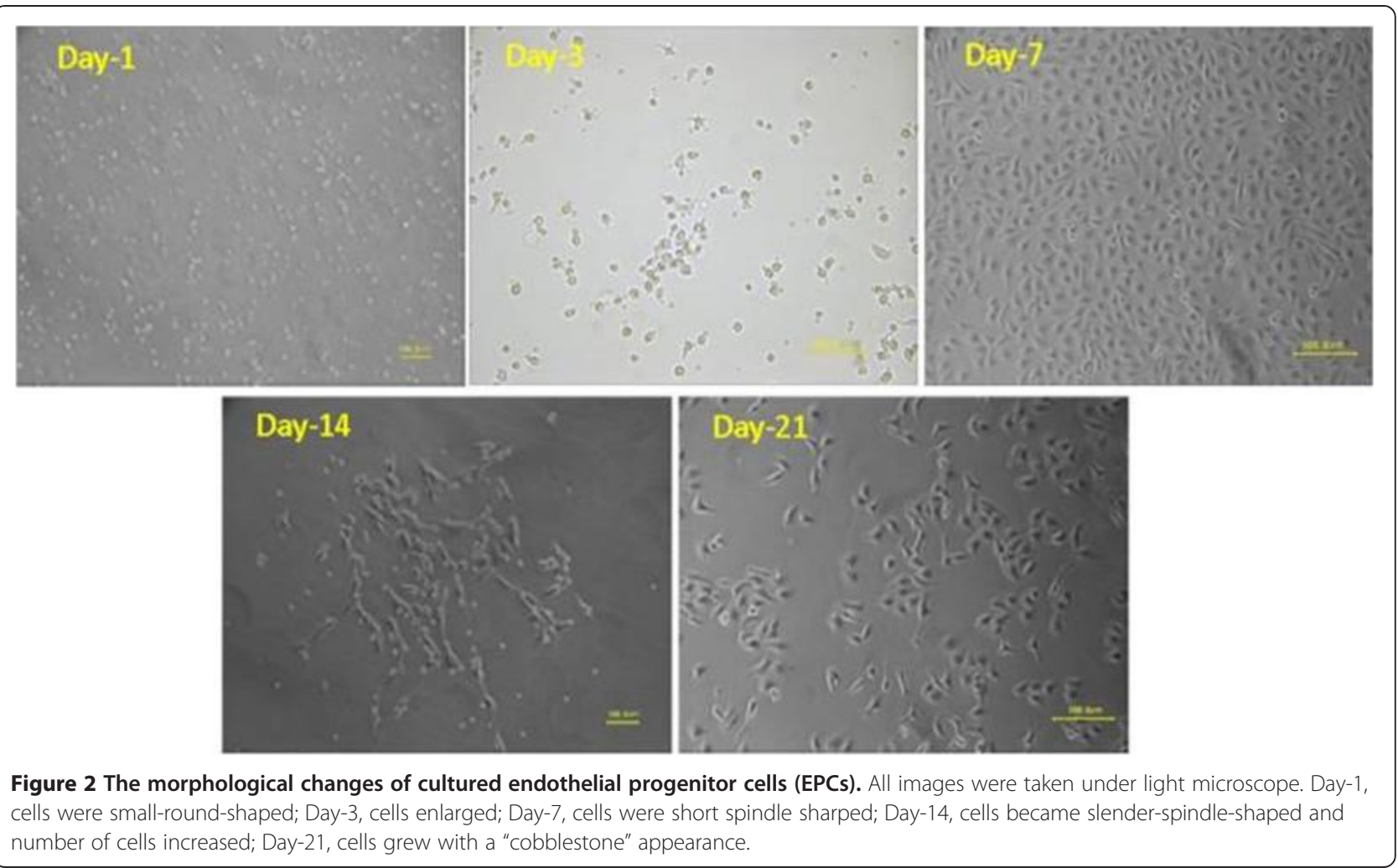


Identify the renal tissue morphology and histochemistry studies

The renal tissues were embedded in paraffin. The sections were cut at 3-4 $\mu \mathrm{m}$ thickness, and stained with $H \& E$ and PAS. Five pictures were taken randomly for each PAS-stained section at 400× magnification, and were analyzed by MetaMorph software (UIC) to calculate the ratio of glomerular ECM area and total glomerular area, which was used as the thickness index of glomerular mesangial matrix. Immunohistochemical staining on renal section was performed with $\mathrm{ABC}$ method. Polyclonal antibodies against CD31, HIF-1 $\alpha$, MCP-1 and CD105 were purchased from Bioss Inc. (Beijing, China). Five pictures were randomly taken for each section at $400 \times$ magnification, and integral optical density (IOD) was calculated by microscopic image analyzer (MetaMorph/ DP10/BX41, UIC/Olympus, USA/Japan). IOD value of CD31 (endothelial cell-specific marker) was used to represent the PTC density.

\section{Western blotting assay}

The total protein was extracted from renal tissue by RIPA lysis buffer (Beyotime Inc., Shanghai, China), and separated by $10 \%$ SDS-PAGE. Then, the separated protein was transferred to nitrocellulose membrane $(70 \mathrm{~V}$ for 1.5 hours). The blots were blocked in 5\% non-fat milk for 1 hour at room temperature, and then incubated with primary antibodies (HIF-1 $\alpha, 1: 500$; MCP-1, 1:500; $\mathrm{CD} 105,1: 400)$ overnight at $4^{\circ} \mathrm{C}$. At the second day, horseradish peroxidase labeled secondary antibody (goat anti-rabbit IgG- HRP, 1:1000) were incubated with the blots at room temperature for 2 hours. Then, the blots were washed and incubated with NBT/BCIP for 10-30 mins. The blots were then scanned and analyzed by GelPro Analyzer software (Media Cybernetics, Silver Spring, MD). The relative expression levels were quantified and normalized to control groups.

\section{Real-time fluorescent quantitative RT-PCR}

Total RNA extracted by TRIzol extraction (Tiangen Inc., Nanjing, China) of kidney homogenates, and quantified by UV spectrophotometer. Purity of RNA was identified by $A_{260} / A_{280}$ ratio and gel electrophoresis. Primers for CD105, MCP-1, HIF- $1 \alpha$ and $\beta$-actin (internal control) were designed with Primer Premier 5.0 software (Palo Alto CA, USA) as shown in Table 1. $2 \mu \mathrm{g}$ of total RNA were reverse-transcribed into cDNA by using TIANScriptcDNA Kits (Tiangen Inc., Nanjing, China). Real-time quantitative

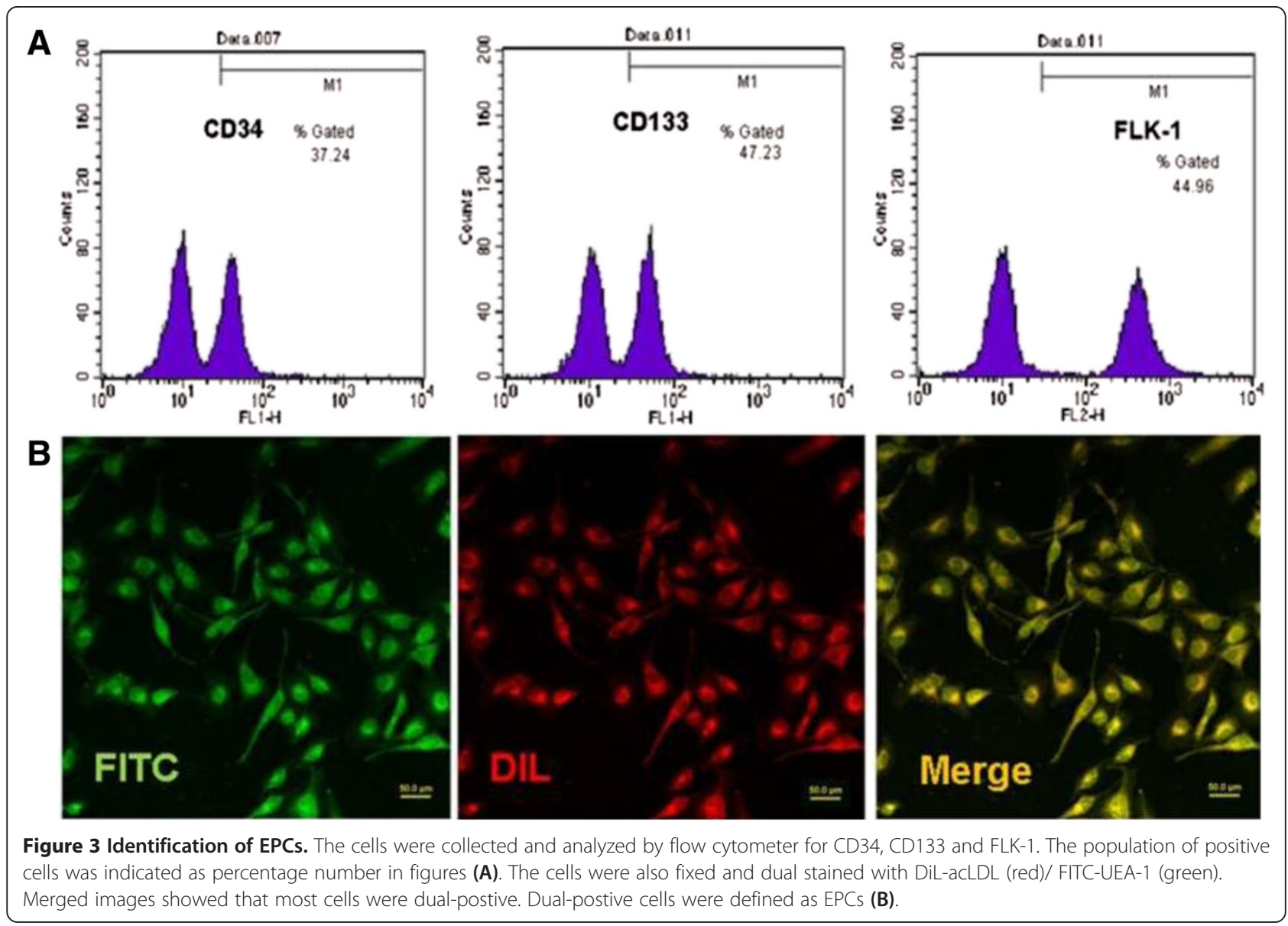




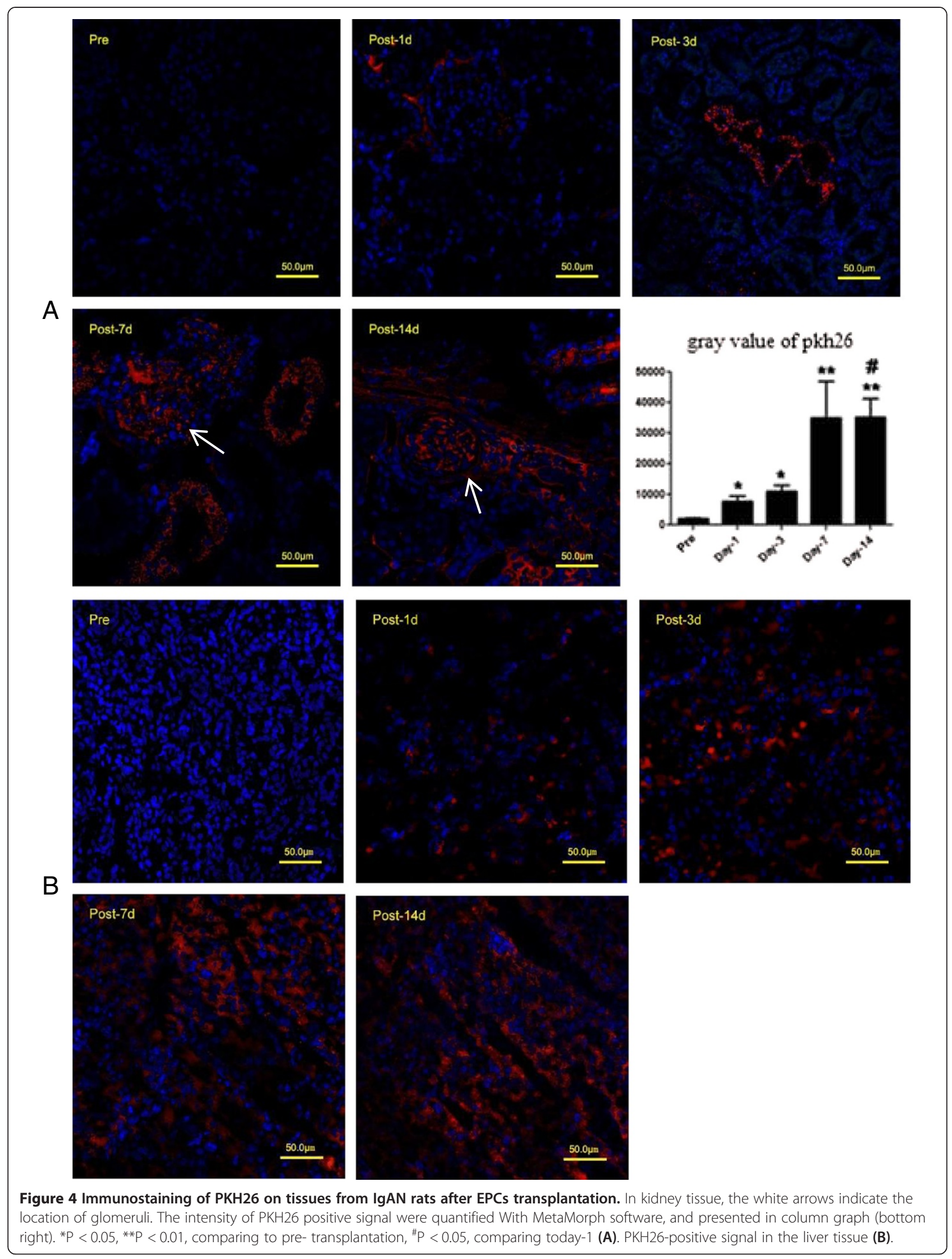


Table 3 Biochemical parameters of Normal, IgAN and EPCs rats groups $(\bar{x} \pm s)$

\begin{tabular}{|c|c|c|c|}
\hline & $\begin{array}{l}\text { Normal } \\
\text { group }\end{array}$ & IgAN group & EPCs group \\
\hline Urine Protein (mg/24 h) & $9.94 \pm 4.03$ & $77.7 \pm 17.1$ & $28.16 \pm 8.04^{* \#}$ \\
\hline $\begin{array}{l}\text { Urinary red blood cell } \\
\text { count(cells } / \mu \mathrm{L})\end{array}$ & $5.17 \pm 0.79$ & $454.35 \pm 72.3$ & $323.68 \pm 32.64^{* *}$ \\
\hline BUN (mmol/L) & $6.57 \pm 0.45$ & $11.02 \pm 1.37$ & $7.88 \pm 0.36^{* \#}$ \\
\hline $\operatorname{Scr}(\mu \mathrm{mol} / \mathrm{L})$ & $26.8 \pm 3.53$ & $55.4 \pm 6.02$ & $35.6 \pm 5.91^{* \#}$ \\
\hline Serum $\lg A(\mu \mathrm{g} / \mathrm{ml})$ & $26.37 \pm 2.49$ & $31.72 \pm 3.73$ & $27.73 \pm 1.65^{* *}$ \\
\hline $\mathrm{ALT}(\mathrm{u} / \mathrm{L})$ & $33.67 \pm 4.76$ & $33.33 \pm 3.82$ & $35.82 \pm 5.71$ \\
\hline AST (u/L) & $86.0 \pm 8.07$ & $86.5 \pm 6.65$ & $88.1 \pm 6.69$ \\
\hline GGT (u/L) & $25.5 \pm 3.27$ & $27.0 \pm 2.19$ & $27.17 \pm 2.48$ \\
\hline ALB $(g / L)$ & $37.67 \pm 2.16$ & $40.17 \pm 2.32$ & $39.23 \pm 2.49$ \\
\hline
\end{tabular}

${ }^{*} P<0.01,{ }^{* *} P<0.05$, compare to IgAN group;

$" P<0.01$, compare to Normal group.

PCR were then performed with SYBR Premix Ex Taq (Clontech, Mountain View, CA) in $20 \mu$ volume, in the following condition: $95^{\circ} \mathrm{C} \times 5 \mathrm{~s}, 60^{\circ} \mathrm{C} \times 20 \mathrm{~s}, 72^{\circ} \mathrm{C} \times 30 \mathrm{~s}$, for 40 cycles. Each sample was measured three times, and the average of $\mathrm{Ct}$ was taken. The relative expressions of mRNA were measured using $2^{-\Delta \Delta C t}$ method.

\section{Statistical analysis}

Data was analyzed with one-way ANOVA analysis of variance using SPSS software 17.0 (IBM, Armonk, NY, USA). Data were presented as the mean \pm S.E.M of at least three measurements. $P<0.05$ was considered as significant in comparison with control.

\section{Results}

\section{Characterization of IgAN animal model}

We examined the physical appearance and biochemical parameters in the rats. IgAN rats were found to show grey hair and slow-growing. 24-hour urine protein, Urinary red blood cell, BUN, Scr and IgA serum level were significantly elevated in IgAN rats. ALT, AST and GGT showed no significant change in IgAN rats after treatment compare to controls. (Table 2) Immunofluorescence studies showed that deposition of IgA was mainly seen at glomerular mesangial area, most of the staining in the IgAN model group was ++ to +++ (Figure 1).

\section{Identify EPCs}

The freshly isolated EPCs were small-round shaped and suspended in culture medium. At day 2, cells started to attach to the dish wall, and cellular hypertrophy was observed at day 3 , followed by becoming short spindle shaped. The cellular growth peak was reached after 7-day culture. At day 10-14, the cells became slender-spindle-shaped and started colony formation. At day 21, cell colony formation was completed with a "cobblestone" appearance, as shown in Figure 2. At day 14, EPCs were identified by CD34, CD133, FLK-1 using flow cytometer. DiL-acLDL (red)/FITC-UEA-1 (green) dual staining cells were observed under the laser scanning confocal microscopy. The cells with dual staining (shown as yellow fluorescence) were considered as differentiating EPCs (Figure 3).

\section{The expression of PKH26}

Cryo-section of kidney and liver tissues stained with PKH26 and incubated with 4', 6-diamidino-2-phenylindole (DAPI). PKH26 positive cells showed red fluorescence, nuclei were stained blue with DAPI under fluorescence microscopy. 1 day after transplantation, PKH26 positive cells were detected in the kidney of EPCs rats, mainly in the interstitial area. 3, 7, 14 days after transplantation, more and more PKH26 positive cells were discovered in glomerular and interstitial areas. The intensity of red fluorescence was gradually increased after transplantation. The difference between day- 1 and day-14 after transplantation was significant. In addition to the kidney, PKH26-positive signal could also be detected in the liver tissue. The significance of this liver migration of EPCs was still waited to be investigated (Figure 4).

\section{Biochemical examination}

24-hour urine protein, Urinary red blood cell, BUN, Scr and IgA serum level in IgAN group increased significantly compared to the ones in normal group. However, these parameters in EPCs group decreased compared to the ones in IgAN group. The differences between groups were statistically significant $(\mathrm{p}<0.01$, Table 3 ). After transplantation, 24-hour urine protein, Urinary red blood cell, BUN, Scr and IgA serum level gradually decreased. The differences between 14 days post-transplantation and

Table 4 Biochemical parameters in EPCs group after transplantation $(\bar{x} \pm s)$

\begin{tabular}{cccccc}
\hline & Day-0 & Day-1 & Day-3 & Day-7 & Day-14 \\
\hline Urine Protein $(\mathrm{mg} / 24 \mathrm{~h})$ & $70.3 \pm 33.2$ & $65.44 \pm 16.9^{\#}$ & $54.22 \pm 16.2^{\#}$ & $28.86 \pm 8.56^{*}$ & $28.16 \pm 8.0^{*}$ \\
Urinary red blood cell count $(\mathrm{cell} / \mathrm{s} / \mathrm{L})$ & $452.72 \pm 45.8$ & $444.5 \pm 42.13^{\#}$ & $432.88 \pm 31.5^{\#}$ & $406.9 \pm 27.01^{\#}$ & $323.68 \pm 32.64^{*}$ \\
BUN (mmol/L) & $10.42 \pm 1.18$ & $10.06 \pm 0.87^{\#}$ & $9.6 \pm 0.85^{\#}$ & $8.76 \pm 0.82^{*}$ & $7.88 \pm 0.36^{*}$ \\
Scr $(\mu \mathrm{mol} / \mathrm{L})$ & $52.8 \pm 6.05$ & $52.6 \pm 9.07^{\#}$ & $45.2 \pm 7.79^{\#}$ & $38.4 \pm 6.73^{*}$ & $35.6 \pm 5.91^{* *}$ \\
Serum $\lg \mathrm{A}(\mu \mathrm{g} / \mathrm{ml})$ & $30.37 \pm 1.74$ & $29.72 \pm 2.24^{\#}$ & $28.88 \pm 1.82^{\#}$ & $28.32 \pm 1.87^{\#}$ & $27.73 \pm 1.65^{*}$ \\
\hline
\end{tabular}

Comparing to Day- $0:{ }^{*} \mathrm{P}>0.05,{ }^{*} \mathrm{P}<0.05$, ${ }^{* *} \mathrm{P}<0.01$. Day-0 is the EPCs rats before receiving EPCs transplantation. 


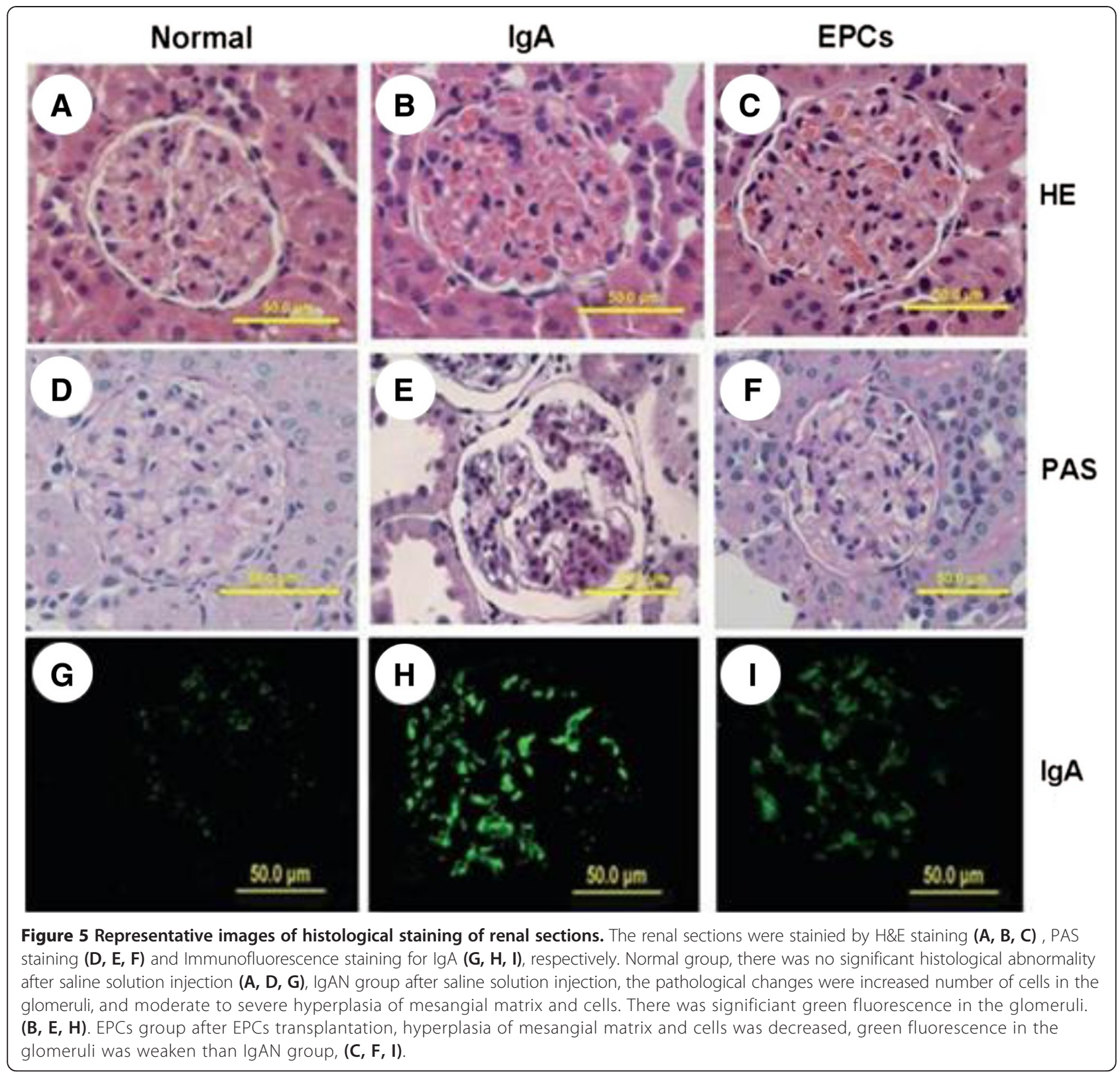

1 day prior to transplantation were statistically significant $(\mathrm{p}<0.01$, Table 4).

\section{Pathological observation of kidney}

Morphology of glomerular, tubular, and renal interstitial remainined normal in normal group. While, in IgAN groups, the number of glomerular mesangial cells increased, mesangial matrix widened, the shape of renal tubules became irregular. In EPCs group, pathological changes of renal mesangial matrix and tubules were significantly alleviated (shown in Figure 5).

The PAS staining showed that in IgAN group, the ratio of ECM area and the corresponding glomerular area was significantly higher than the ratio in normal group $(p<$
0.01), suggesting the accumulation of renal glomerular ECM. However, in EPCs group, the deposition of renal glomerular ECM decreased significantly, shown by lower ratio of ECM area and the corresponding glomerular area $(\mathrm{p}<0.01)$ (Figure 5 and Table 5).

Table 5 The ratio of ECM to total glomerular area (ECM/ TGA) and PTC density in normal/lgAN/EPCs group $(\bar{x} \pm s)$

\begin{tabular}{llll}
\hline & Normal group & IgAN group & EPCs group \\
\hline ECM/TGA(\%) & $0.44 \pm 0.58$ & $11.06 \pm 1.4 \#$ & $5.59 \pm 1.94^{* \#}$ \\
PTC density (A) & $44.75 \pm 10.26$ & $17.93 \pm 4.15 \#$ & $30.9 \pm 3.37^{* \#}$
\end{tabular}

${ }^{*} \mathrm{P}<0.01$ compare to IgAN group; \#P $<0.01$ compare to normal group. 


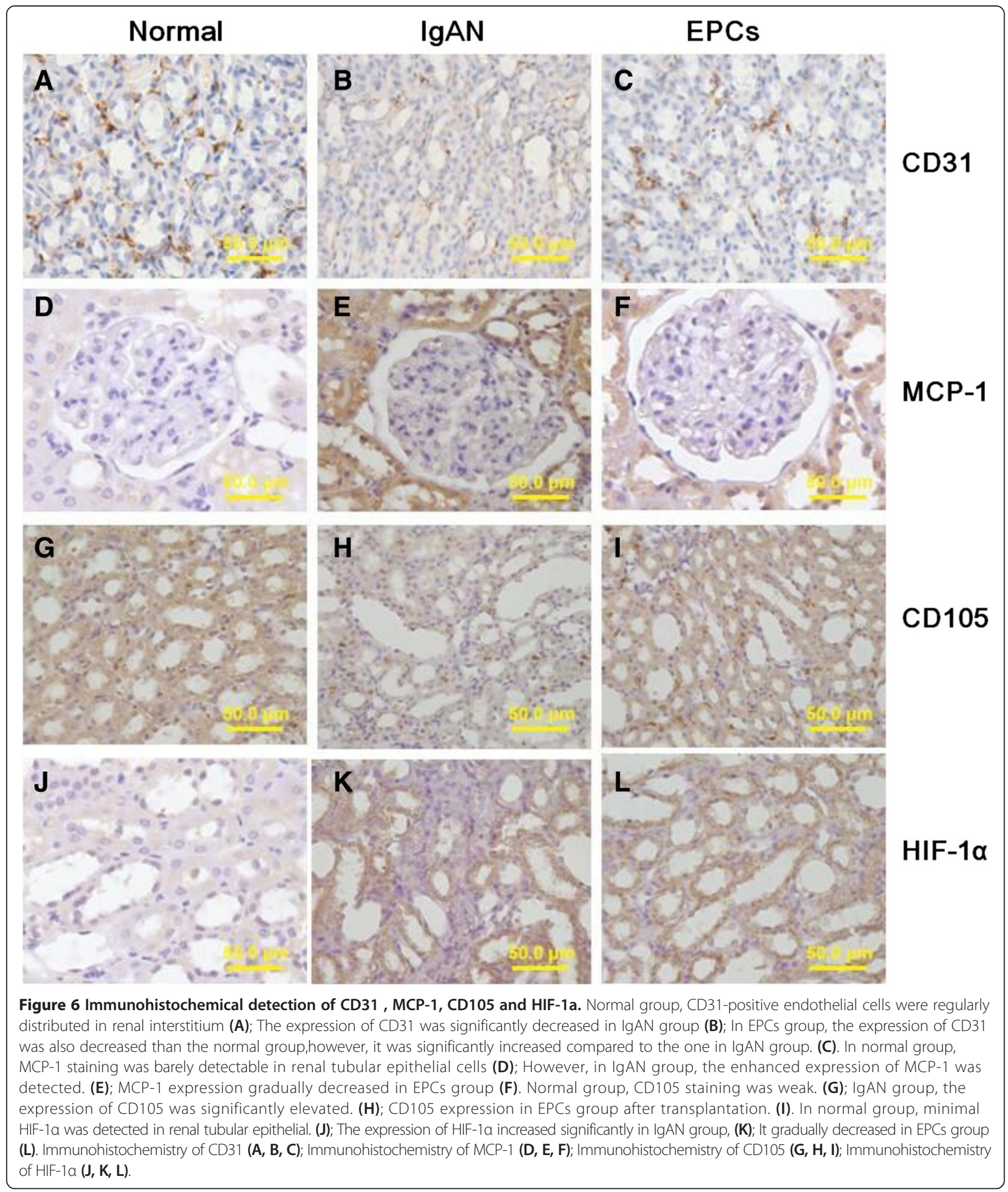

\section{Immunofluorescence of $\lg A$}

Immunofluorescence staining of IgA showed slight IgA deposition in normal rats and the fluorescence intensity was scored as "-" to "+". In contrast, IgAN rats had significant granule-like green fluorescence in the glomeruli which was scored as "++" to "++++", these results indicated successful establishment of IgAN. EPC rats had significantly reduced green fluorescence in the glomeruli which was scored as "+" to "+++" compare to IgAN rats (Figure 5). 
Table 6 The ratio of ECM to total glomerular area (ECM/TGA) and PTC density in EPCs group after transplantation $(\bar{x} \pm \mathbf{s})$

\begin{tabular}{llllll}
\hline & Day-0 & Day-1 & Day-3 & Day-7 & Day-14 \\
\hline ECM/TGA(\%) & $11.06 \pm 1.94$ & $10.57 \pm 1.8 \#$ & $8.94 \pm 1.71^{*}$ & $8.62 \pm 1.13^{* *}$ & $6.05 \pm 1.49^{* *}$ \\
PTC density (A) & $13.69 \pm 3.54$ & $14.96 \pm 3.34 \#$ & $19.26 \pm 3.01^{*}$ & $24.62 \pm 3.88^{* *}$ & $30.9 \pm 3.37^{* *}$ \\
\hline
\end{tabular}

Comparing to Day-0: ${ }^{\#} \mathrm{P}>0.05,{ }^{*} \mathrm{P}<0.05,{ }^{* *} \mathrm{P}<0.01$. Day- 0 is the EPCs rats before receiving EPCs transplantation.

\section{Immunohistochemistry}

In normal group, CD31 was shown as brown fine deposits on the membrane of endothelial cells of PTC, which were distributed in renal interstitium among renal tubules; some was shown on the membrane of glomerular vascular endothelial cells. The expression of CD31 was significantly decreased in IgAN group as a comparison to the normal group, while the expression of CD31 in EPCs group was significantly increased compared to the one in IgAN group. Integrated optical density (IOD) value of CD31 was used to represent the density of peritubular capillary. The difference between groups was statistically significant (Figure 6, Tables 5 \& 6).

In normal group, $\mathrm{MCP}-1$ staining was barely detectable in renal tubular epithelial cells. However, in IgAN group, the enhanced expression of $\mathrm{MCP}-1$ was detected. After EPCs transplantation, MCP-1 expression gradually decreased at day-3, day-7 and day-14 (Figure 6).

In normal group, CD105 staining was weak in stromal vascular endothelial cells and glomerular/interstitial cells. While in IgAN group, the expression of CD105 was significantly elevated prior to transplantation. CD105 expression in EPCs group diminished at day-3 after EPCs transplantation, while it increased at day 7 and day 14 (Figure 6).

In normal group, minimal HIF- $1 \alpha$ was detected in renal tubular epithelial. The expression of HIF-1 $\alpha$ increased significantly in IgAN group, while it gradually decreased in EPCs group (Figure 6).
Protein and mRNA levels of MCP-1, HIF-1a and CD105

To confirm the expression prolife of the molecules we observed in immuno- histochemistry studies, we measured the expression again by using quantitative western blotting or quantitative RT-PCR. Similarly, we found that normal group express relatively less amount of MCP-1, HIF- $1 \alpha$, which were significantly higher in IgAN groups. However, after EPC transplantation, MCP-1, HIF- $1 \alpha$ expression was gradually decreased in 14 days. The protein expression of CD105 was decreased in the first 3 days after transplantation, while it increased in day-7 and day-14. mRNA of these molecules showed the similar results. mRNA levels of MCP-1 and HIF- $1 \alpha$ were significantly increased in IgAN group, while the levels were gradually decreased in 14 days after transplantation. CD105's mRNA first increased in the first 7 days after transplantation, but it increased and reached the peak at day-14 (Figures 7, 8 \& 9).

\section{Discussion}

Currently, IgAN is considered as a very severe immune disease, on which there is no proper and successful treatment. Our research aims to control or improve the pathogenesis of renal tissue in IgAN rat model, by PKH26-labeled EPCs transplantation. IgAN rat model was established by a combined injection of USA, LPS and CCL4. Hematuria and proteinuria were observed in the treated rats at 6 weeks post-injury and some of IgAN rats developed gross hematuria (data not shown). Obvious
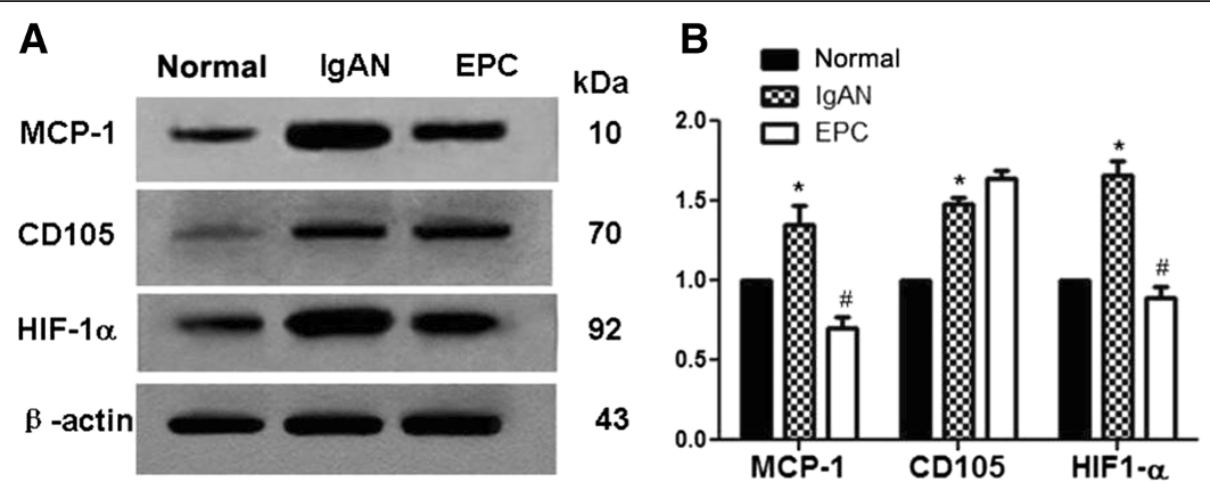

Figure 7 Protein expression of MCP-1, CD105 and HIF-1a after transplantation. Representative immunoblots (A) and quantitative densitometry analysis (B, from $\mathbf{5}$ experiments) demonstrating protein expression of MCP-1, CD105 and HIF-1a, in the renal cortex of rats from normal, IgAN and EPCs groups. ${ }^{*} \mathrm{P}<0.05$ vs normal, ${ }^{\#}<0.05$ vs IgAN. 


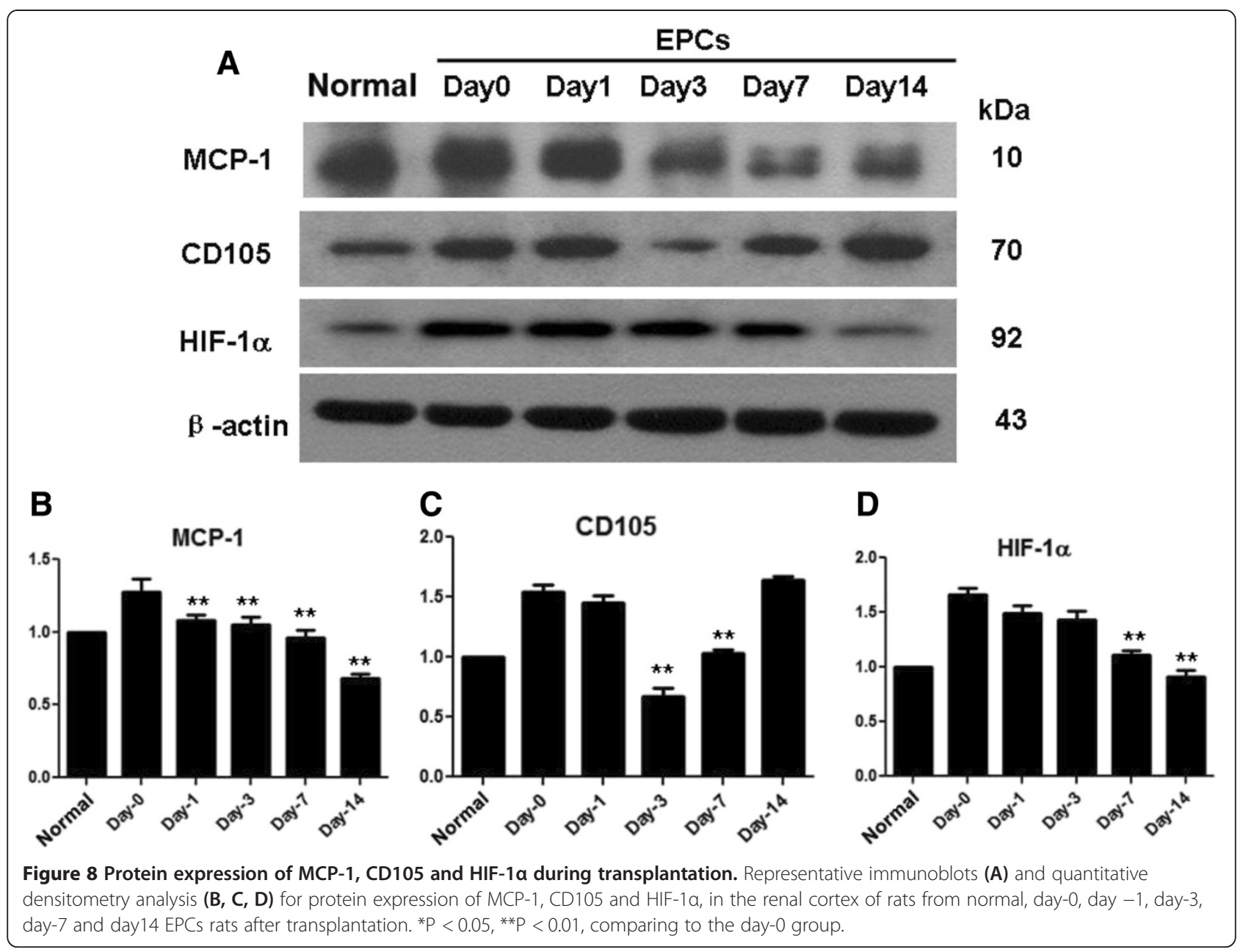

IgA deposition in the glomeruli of these animals could also been detected. These findings indicate a successful establishment of IgAN model in rats. One day after the transplantation, the PKH26-labeled cells started to express mainly in renal interstitial area. At the day 3, 7, 14, the number of PKH26-labeled cells in the renal interstitial and glomerular area gradually multiplied, indicating that intravenous injected BM-EPCs can be re-located to the damaged kidneys. It was observed that urinary red blood cell, 24- hour urine protein, BUN and Scr dramatically decreased as well as the improvement of renal pathological findings in EPCs group comparing to IgAN group. Other markers, such as HIF-1 $\alpha$ and MCP-1 expression increased in IgAN group but decreased in EPCs group. While CD105 was an exception, the expression of CD105 sustained at a high level when EPCs were transplanted. All these data suggested that BM-EPCs transplantation significantly decreases the levels of inflammatory factors, and improved ischemic- induced renal tissue hypoxia.

The conventional immunosuppressive treatment, such as the corticosteroid and cytotoxic drugs, the application of ACEI and ARB have been introduced into the treatment of IgAN for many years, however, all these methods are not effective, especially for IgAN patient's prognoses [13,14]. Among all the factors which affect IgAN prognoses, renal interstitial fibrosis is one of the most independent risk factors. PTC provides the major blood supply for renal tubule-interstitium; and much evidence has suggested that loss of PTC is mainly due to ischemic injury and fibrosis of renal tubule-interstitium. One major feature of PTC pathology is the decreased number of capillary endothelial cells. Therefore, repair or regeneration of endothelial cells and reducing microvascular loss will be the promising therapeutic treatment for IgAN. Endothelial progenitor cell-mediated therapeutic angiogenesis could be an effective way to control or improve a wide variety of pathological condition. In recent years, EPCs therapy has become a hot spot in the treatment of heart disease, stroke, peripheral arterial disease, rheumatism, cancer and other diseases [15-18]. In our laboratory, recent data showed that the cell number of bone marrow EPCs in IgAN rats was signficantly less than that of normal rats by $33.3 \%$; the migration rate of these cells in IgAN rats was decreased by $10 \%$; the proliferation rate 


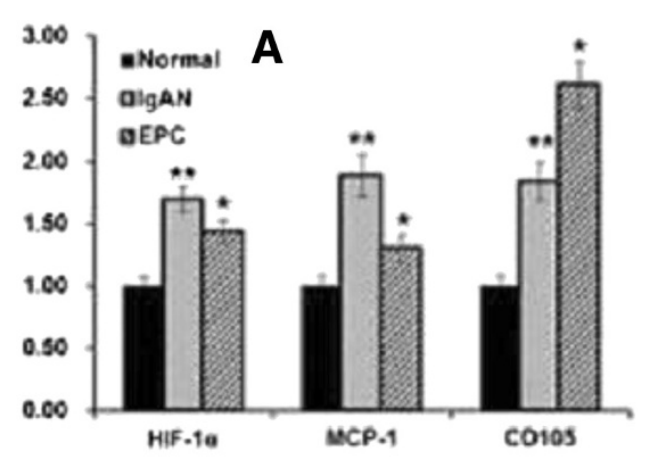

$\mathbf{B}$
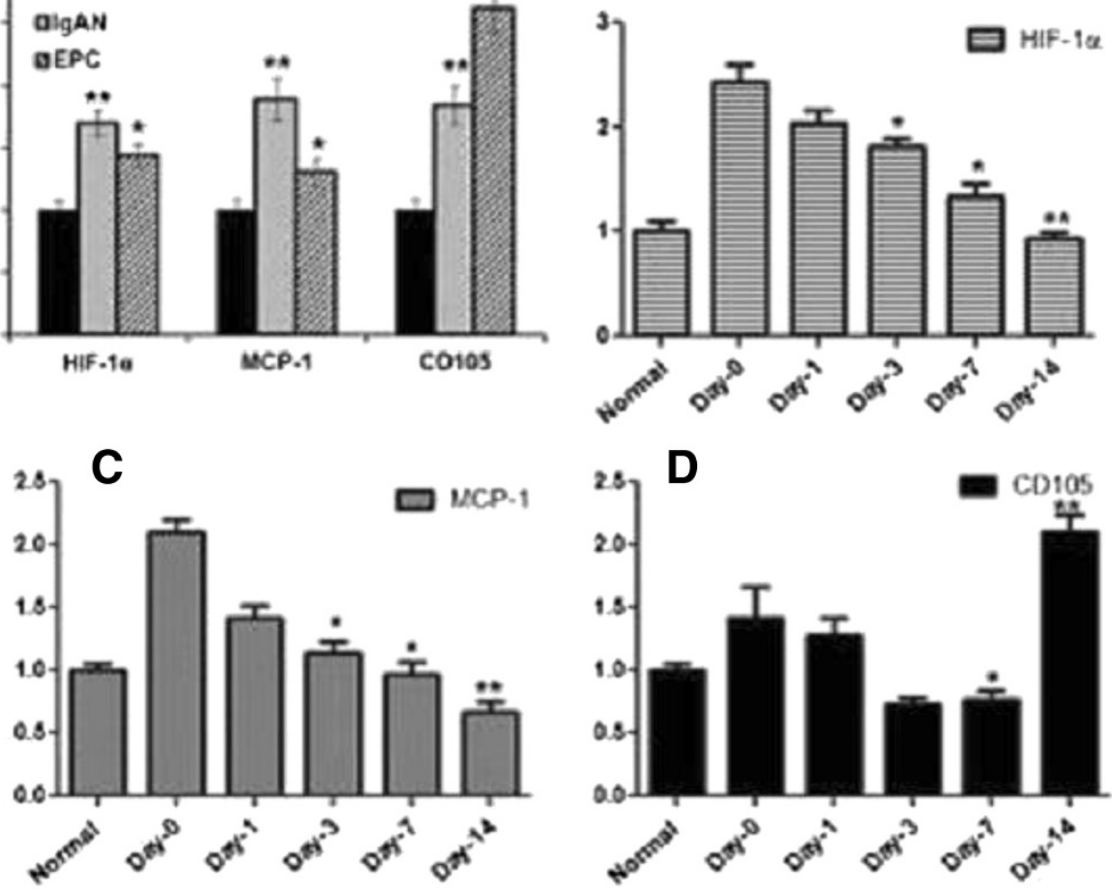

Figure 9 mRNA level of MCP-1, CD105 and HIF-1a. Real-time quantitative RT-PCR analysis of MCP-1, CD105 and HIF-1a mRNA after transplantation. ${ }^{*} \mathrm{P}<0.05 \mathrm{vs}$ normal, ${ }^{*} \mathrm{P}<0.05 \mathrm{vs}$ IgAN. (A). MCP-1, CD105 and HIF-1a mRNA from the renal cortex of rats isolated from normal, day-0, day -1 , day-3, day-7 and day 14 EPCs rats after transplantation. ${ }^{*} P<0.05$, ${ }^{* *} P<0.01$, comparing to the day-0 group (B, C, D).

of these cells was decreased by $18 \%$, which were all statistically significant comparing to that of normal rats (unpublished data). To continue the studies, here we tried to treat IgAN rats with exogenous EPCs transplantation. The results showed that BM-EPCs can re-locate in the kidney of IgAN rats. The IgAN rats receiving EPCs have significantly improved kidney function, reduced expansion of glomerular extracellular matrix, attenuated IgA deposits in the glomeruli and increased density of peritubular capillary.

CD105, known as endoglin, is a type-I glycoprotein on cellular membrane. CD105 is predominately expressed in vascular endothelial cells and related tissues, while is absent in lymphatic endothelial cells [19]. Different from pan-vascular endothelial cell markers, CD105 is only strongly expressed in highly proliferating vascular endothelial cells, while weakly or not expressed in vascular endothelial cells in normal adult tissues. Other researchers have found that in the case of inflammation occurring on skin lesion, the up-regulation of CD105 promptly accelerated the infiltration of inflammatory cells and angiogenesis [20]. Our research also showed the higher expression of CD105 in the kidney tissue of IgAN rats, which might due to the elevated inflammatory responses in IgAN rats. CD105 expression decreased 3 days after EPCs transplantation, indicating the reduced inflammatory responses. At the day- 7 and day14 after transplantation, CD105 level increased gradually comparing to the day-3. We speculate this change might due to the process that relocated EPCs were transformed into actively proliferating vascular endothelial cells.

Another marker for vascular endothelial cells is CD31, which is highly expressed at the cellular junctions between vascular endothelial cells. Therefore, in this study, the number of CD31 positive cells was used to represent PTC density. In our research, CD31 positive staining was dramatically decreased in the kidney tissue of IgAN group comparing to that of normal group, indicating a decreased PTC. 7 and 14 days after transplantation, in EPCs group, the number of CD31 positive cells was increased, suggesting an increasing PTC density in EPCs group comparing to that in IgAN group.

Previous studies have shown that hypoxia is a major factor for cellular damage and angiogenic dysregulation. Hypoxia can induce the expression of certain genes and then affect cellular function, which is one of the important mechanisms for the initiation and development of renal interstitial fibrosis [21-23]. The declining of PTC density often leads to tubule-interstitial in a hypoxic state. Hypoxia-inducible factor $1-\alpha$ (HIF-1 $\alpha)$ is a transcription factor in cells growing at low oxygen concentration, which plays an essential role in cellular and 
systematic responses to hypoxia $[24,25]$. Therefore, HIF$1 \alpha$ is often used as a sensitive indicator for hypoxia. Our study showed that HIF-1 $\alpha$ expression increased in the kidney tissues of IgAN rats, while decreased in EPCs rats $(p<0.05)$, indicating that EPCs transplantation could improve hypoxic condition of tubule-interstitial. This result is consistent with the observation that PTC density was increased in EPCs rats.

MCP-1 is an inflammatory chemokine. Local overexpression of MCP-1 at vessel wall induces infiltration and aggregation of mono-nuclear cells, and cause formation of atherosclerotic lesion [26]. It also promotes the expression of important cytokines which cause fibrosis, such as IL-6, TGF- $\beta$, etc. In kidney, overexpression of MCP-1 results in the accumulation of extracellular matrix in glomerular and tubules, causing glomerulosclerosis and renal interstitial fibrosis, eventually leading to renal failure [27]. Only trace expression of MCP-1 was detected in renal mesangial cells, renal tubular epithelial cells, vascular endothelial cells and other cells under normal circumstances. However, MCP-1 is induced and highly expressed under many other conditions, such as hypoxia, immune responses, viral infection, injury, hemodynamic changes, etc. [28,29], which is in agreement with our observation. We found that MCP-1 expression was enhanced in the kidney of IgAN group comparing to the normal group, while it declined after EPCs transplantation. The differences between day-7/14 and day-prior-to transplantation were statistically significant.

In IgAN pathogenesis, ECM expansion or mesangial proliferation is often associated with serum elevation of IgA-IgG2a IC and enhanced deposition of IgA, as well as cytokine production such as IL- 6 and TGF- $\beta$. Therefore, in this study the ratio of the ECM area to glomerular cross-sectional area was determined to represent the degree of nephropathy in IgAN experimental rats. We found that this ratio was significantly decreased in EPCs transplanted rats, comparing to IgAN group, suggesting that EPCs transplantation can cause a decline in the deposition of ECM in mesangial area. It's been known that the increased synthesis and declined degradation of ECM are the important factors causing the development of glomerulosclerosis [30-32]. Therefore, in theory, EPC transplantation may further delay the progress of glomerular sclerosis, which may need further investigation.

In summary, our findings suggested that BM-EPCs were re-located to the damaged kidneys and improve the pathogenesis of renal tissue in IgAN rat. It seemed provided a practically effective way for treating IgAN patients.

\section{Conclusion}

EPCs transplantation in IgAN rats promotes angiogenesis, resulting in an increased PTC density. It also significantly down-regulates HIF-1 $\alpha$, MCP-1 expression, relieves tissue ischemia, improves hypoxia and inflammatory infiltration. In transplanted IgAN rats, the expansion of extracellular matrix in glomerular was reduced; renal pathogenesis progression was slowed, and renal function was improved. All these data establish the experimental fundament for the new therapies of IgAN.

\section{Additional file}

\section{Additional file 1: ARRIVE checklist.}

\section{Competing interest}

The authors declare that they have no competing interests.

\section{Authors' contribution}

WG (designed and finalized most of the work), JMF (conceived of the study and revised the article), LY (participated in the design of the study), LS (drafted the manuscript and performed the statistical analysis), GQZ (participating in the work of cell culture), All authors read and approved the final manuscript.

\section{Acknowledgements}

The authors are grateful to Professor Zhihui Hao, ShenYang Pharmaceutical University, for the excellant technical assistance of animal experiments. This work is supported by Liaoning Provincial Department of Education, Science and Technology Research Fund (L2011134); The Social Development Research Plan of Liaoning Province, China (grant no.201225094).

\section{Author details}

${ }^{1}$ Department of Nephrology, The Fourth Hospital of People, Shenyang 110020, China. ${ }^{2}$ Department of Nephrology, The First Affiliated Hospital of China Medical University, Shenyang 110001, China. ${ }^{3}$ Department of Meical Ultrasound, The Fourth Hospital of People, Shenyang 110020, China.

Received: 28 October 2013 Accepted: 2 July 2014

Published: 9 July 2014

\section{Reference}

1. Berger J, Hinglais N: Intercapillary deposits of IgA-lgG. J Urol Nephrol (Paris) 1968, 74(9):694-695.

2. Choi YJ, Chakraborty S, Nguyen V, Nguyen C, Kim BK, Shim SI, Suki WN, Truong LD: Peritubular capillary loss is associated with chronic tubulointerstitial injury in human kidney: altered expression of vascular endothelial growth factor. Hum Pathol 2000, 31(12):1491-1497.

3. Ohashi R, Kitamura H, Yamanaka N: Peritubular capillary injury during the progression of experimental glomerulonephritis in rats. J Am Soc Nephrol 2000, 11(1):47-56.

4. Kang DH, Joly AH, Oh SW, Hugo C, Kerjaschki D, Gordon KL, Mazzali M, Jefferson JA, Hughes J, Madsen KM, Schreiner GF, Johnson RJ: Impaired angiogenesis in the remnant kidney model: I. Potential role of vascular endothelial growth factor and thrombospondin-1. J Am Soc Nephrol 2001, 12(7):1434-1447.

5. Kang DH, Hughes J, Mazzali M, Schreiner GF, Johnson RJ: Impaired angiogenesis in the remnant kidney model: II. Vascular endothelial growth factor administration reduces renal fibrosis and stabilizes renal function. J Am Soc Nephrol 2001, 12(7):1448-1457.

6. Asahara T, Murohara T, Sullivan A, Silver M, van der Zee R, Li T, Witzenbichler B, Schatteman G, Isner JM: Isolation of putative progenitor endothelial cells for angiogenesis. Science 1997, 275(5302):964-967.

7. Reyes M, Dudek A, Jahagirdar R, Koodie L, Marker PH, Verfaillie CM: Origin of endothelial progenitors in human postnatal bone marrow. J Clin Invest 2002, 109(3):337-346.

8. Emancipator SN: Animal models of IgA nephropathy. Curr Protoc Immunol 2001, 11:Unit.15

9. Peng W, Liu ZR: Comparison of two rat models of IgA nephropathy. J South Med Univ 2008, 28(10):1842-1845. in Chinese. 
10. Tang $Y$, Lou TQ, Cheng CL: The modification of laboratory IgA nephropathy model. J Zhongshan Univ (Med) 2006, 27(2):184-187.

11. Hur J, Yoon CH, Kim HS, Choi JH, Kang HJ, Hwang KK, Oh BH, Lee MM, Park YB: Characterization of two types of endothelial progenitor cells and their different contributions to neovasculogenesis. Arterioscler Thromb Vasc Biol 2004, 24(2):288-293.

12. Gulati R, Jevremovic D, Peterson TE, Witt TA, Kleppe LS, Mueske CS, Lerman A, Vile RG, Simari RD: Autologous culture-modified mono- nuclear cells confer vascular protection after arterial injury. Circulation 2003, 108 (12):1520-1526.

13. Boyd JK, Cheung CK, Molyneux K, Feehally J, Barratt J: An update on the pathogenesis and treatment of IgA nephropathy. Kidney Int 2012, 81(9):833-843.

14. Floege J, Eitner F: Current therapy for IgA nephropathy. J Am Soc Nephrol 2011, 22(10):1785-1794.

15. Fadini GP, Coracina A, Baesso I, Agostini C, Tiengo A, Avogaro A, de Kreutzenberg SV: Peripheral blood CD34 + KDR + endothelial progenitor cells are determinants of subclinical atherosclerosis in a middle-aged general population. Stroke 2006, 37(9):2277-2282

16. Prunier F, Pfister O, Hadri L, Del Monte F, Liao R, Hajjar RJ: Delayed erythropoietin therapy reduces post-MI cardiac remodeling only at a dose that mobilizes endothelial progenitor cells. Am J Physiol Heart Circ Physiol 2007, 292(1):522-529.

17. Hess DC, Hill WD, Martin-Studdard A, Carroll J, Brailer J, Carothers J: Bone marrow as a source of endothelial cells and NeuN-expressing cells After stroke. Stroke 2002, 33(5):1362-1368.

18. Akita T, Murohara T, Ikeda H, Sasaki K, Shimada T, Egami K, Imaizumi T: Hypoxic preconditioning augments efficacy of human endothelial progenitor cells for therapeutic neovascularization. Lab Invest 2003, 83(1):65-73.

19. Baier PC, Schindehütte J, Thinyane K, Flügge G, Fuchs E, Mansouri A, Paulus W, Gruss $P$, Trenkwalder C: Behavioral changes in unilaterally 6-hydroxy-dopamine lesioned rats after transplantation of differentiated mouse embryonic stem cells without morphological integration. Stem Cells 2004, 22(3):396-404.

20. Ji KH, Xiong J, Fan LX, Hu KM, Liu HQ: Rat marrow-derived multipotent adult progenitor cells differentiate into skin epidermal cells in vivo. J Dermatol 2009, 36(7):403-409.

21. Eckardt KU, Bernhardt WM, Weidemann A, Warnecke C, Rosenberger C, Wiesener MS, Willam C: Role of hypoxia in the pathogenesis of renal disease. Kidney Int Supp/ 2005, 99:S46-S51.

22. Nangaku M: Chronic hypoxia and tubulointerstitial injury: a final common pathway to end-stage renal failure. J Am Soc Nephrol 2006, 17(1):17-25.

23. Haase VH: Hypoxia-inducible factors in the kidney. Am J Physiol Renal Physiol 2006, 291(2):271-281.

24. Cheng Q, Nguyen T, Song HX, Bonanno J: Hypoxia protects human corneal endothelium from tertiary butyl hydroperoxide and paraquat-induced cell death in vitro. Exp Biol Med (Maywood) 2007 232(3):445-453

25. Connes P, Perrey S, Varray A, Préfaut C, Caillaud C: Faster oxygen uptake kinetics at the onset of submaximal cycling exercise following 4 weeks recombinant human erythropoietin ( $r$-HuEPO) treatment. Pflugers Arch 2003, 447(2):231-238.

26. Viedt C, Dechend R, Fei J, Hänsch GM, Kreuzer J, Orth SR: MCP-1 induces inflammatory activation of human tubular epithelial cells: involvement of the transcription factors, nuclear factor- kappaB and activating protein-1. J Am Soc Nephrol 2002, 13(6):1534-1547.

27. Murali NS, Ackerman AW, Croatt AJ, Cheng J, Grande JP, Sutor SL, Bram RJ, Bren GD, Badley AD, Alam J, Nath KA: Renal upregulation of HO-1 reduces albumin-driven MCP-1 production: implications for chronic kidney disease. Am J Physiol Renal Physiol 2007, 292(2):F837-F844.

28. Yadav A, Saini V, Arora S: MCP-1: chemoattractant with a role beyond immunity: a review. Clin Chim Acta 2010, 411(21-22):1570-1579.

29. Grandaliano G, Gesualdo L, Ranieri E, Monno R, Montinaro V, Marra F Schena FP: Monocyte chemotactic peptide-1 expression in acute and chronic human nephritides: a pathogenetic role in interstitial monocytes recruitment. J Am Soc Nephrol 1996, 7(6):906-913.

30. Ostendorf T, Kunter U, van Roeyen C, Dooley S, Janjic N, Ruckman J, Eitner F, Floege J: The effects of platelet-derived growth factor antagonism in experimental glomerulonephritis are independent of the transforming growth factor-beta system. J Am Soc Nephrol 2002, 13(3):658-667.

31. Pozzi A, Voziyan PA, Hudson BG, Zent R: Regulation of matrix synthesis, remodeling and accumulation in glomerulosclerosis. Curr Pharm Des 2009, 15(12):1318-1333.

32. Catania JM, Chen G, Parrish AR: Role of matrix metalloproteinases in renal pathophysiologies. Am J Physiol Renal Physiol 2007, 292(3):905-911.

doi:10.1186/1471-2369-15-110

Cite this article as: Guo et al.: Transplantation of endothelial progenitor cells in treating rats with IgA nephropathy. BMC Nephrology 2014 15:110.

\section{Submit your next manuscript to BioMed Central and take full advantage of:}

- Convenient online submission

- Thorough peer review

- No space constraints or color figure charges

- Immediate publication on acceptance

- Inclusion in PubMed, CAS, Scopus and Google Scholar

- Research which is freely available for redistribution

Submit your manuscript at www.biomedcentral.com/submit
C Biomed Central 